\title{
Mining the posterior cingulate: Segregation between memory and pain components
}

\author{
Finn Årup Nielsen ${ }^{1,2}$, Daniela Balslev ${ }^{1,3}$, Lars Kai Hansen ${ }^{2}$ \\ ${ }^{1}$ Neurobiology Research Unit, Copenhagen University Hospital, Copenhagen, Denmark; \\ ${ }^{2}$ Informatics and Mathematical Modelling, Technical University of Denmark, Lyngby, Denmark; \\ ${ }^{3}$ Danish Research Centre for Magnetic Resonance, Hvidovre, Denmark.
}

August 2, 2004

\begin{abstract}
We present a general method for automatic meta-analyses in neuroscience and apply it on text data from published functional imaging studies to extract main functions associated with a brain area - the posterior cingulate cortex. Abstracts from PubMed are downloaded, words extracted and converted to a bag-of-words matrix representation. The combined data is analyzed with hierarchical non-negative matrix factorization. We find that the prominent themes in the PCC corpus are episodic memory retrieval and pain. We further characterize the distribution in PCC of the Talairach coordinates available in some of the articles. This shows a tendency to functional segregation between memory and pain components where memory activations are predominantly in the caudal part and pain in the rostral part of PCC.
\end{abstract}

Keywords: Meta-analysis; PubMed; Positron-emission Tomography; Magnetic resonance imaging; Cingulate gyrus; Brain Mapping; Memory; Pain; Alzheimer Disease; Automatic Data Processing; Bibliometrics.

\section{Introduction}

Functional neuroimaging methods such as positron emission tomography (PET) or functional magnetic resonance imaging (fMRI) map function to brain anatomy by manipulating behavior and measuring a change in regional activity. The resulting maps are used to infer the principles of brain function. The accuracy of these functional maps however, depends critically on the specificity of the behavioral paradigm and on the sensitivity of the analytical tools for detecting the interesting signal. In any individual study, it is very difficult, if not impossible to avoid the particular subject's in part irreproducible behavior and it is not possible a priori to describe the spatiotemporal characteristics of the signal necessary for accurate modelling and detection. Investigating the consensus among results from a large number of brain imaging studies can overcome the problem of false positive and false negative results. Furthermore, neuroimaging studies may discover unexpected changes in activity in areas that so far have not been associated with a given behavior, thus generate new hypotheses. Unexpected activations may be genuine, showing a novel and interesting association between brain and behavior or spurious, for instance a false positive activation from some uninteresting behavior that the paradigm did not control for. If such changes are repeatedly encountered over a large number of different paradigms that addressed the same behavioral function, then it is probable that they are of significance and deserve further investigation.

The potential for data mining across neuroimaging studies has already been recognized and exploited to investigate the consistency of activation patterns associated with a given brain function 


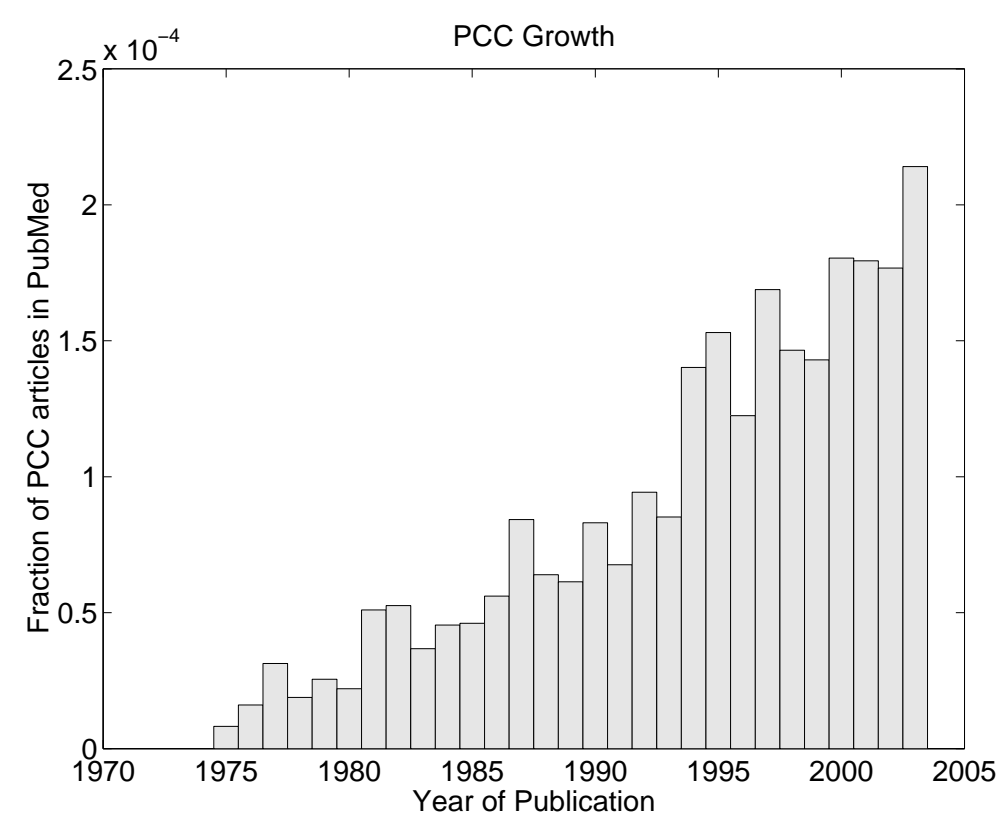

Figure 1: Number of posterior cingulate entries in the PubMed database as a function of the year of publication. The query was "("posterior cingulate" OR "posterior cingulum" OR "retrosplenial" OR "retrosplenium")". It is normalized with the total number of entries of each year in the PubMed database.

(Cabeza and Nyberg, 2000) or to generate new hypotheses about the function of a given brain area (Bush et al., 2000; Maguire, 2001; Maddock, 1999). In these papers, the authors manually generate tables and figures that summarize results across a large number of studies in order to inspect for consensus. The expanding number of published studies however, makes it increasingly time-consuming for the individual researcher to generate exhaustive result summaries. Here, we propose an automatic method which can extract from the neuroimaging literature the consensus about the functions of a given brain area. This method is thought to assist researchers by providing a quick summary of a large number of scientific publications. To illustrate the approach we apply this method to extract functions that are consistently associated with the posterior cingulate cortex (PCC). To this end we have used article abstracts indexed by PubMed under the keywords that relate to both PCC and functional imaging methods.

Despite the increasing attention that this area has attracted over the years (see figure 1), there is no "textbook" consensus about the functions undertaken by this area. Different reviews associate this area with a variety of brain functions, e.g., evaluative functions (for spatial orientation and memory) (Vogt et al., 1992), successful episodic memory retrieval (Cabeza and Nyberg, 2000), emotion (Maddock, 1999), navigation (Maguire, 2001), visuospatial attention (Mesulam et al., 2001; Small et al., 2003), pain (Bromm, 2001), and "resting state" (Shulman et al., 1997; Binder et al., 1999; Mazoyer et al., 2001; Raichle et al., 2001).

Our method is two-stage: In the first stage we will make unsupervised text mining in the form of clustering based on the words in abstracts of PubMed that mention our specific target area (the PCC), and we compare these results with the results reported by previous manual reviews to assess the validity of this automatic analysis. In the second stage we use the Talairach coordinates (Talairach and Tournoux, 1988) within the clustered articles and describe the spatial distribution in terms of the cluster labels from the first stage. This is in order to test whether the functional clusters are anatomically segregated within the posterior cingulate cortex. 
That is, in terms of PCC we ask whether our machine-based methodology is able to capture themes in alignment with major reviews and whether there is functional segregation within the PCC.

\section{Method}

We download abstracts from the PubMed Web-service by restricting the search to posterior cingulate area and functional neuroimaging with the following query:

("posterior cingulate" OR "posterior cingulum" OR "retrosplenial" OR "retrosplenium")
AND ("magnetic resonance imaging" OR "positron emission tomography")

The abstracts are brought on matrix form: $\mathbf{X}(N \times Q)$ where $N$ corresponds to the number of abstracts and $Q$ corresponds to the number of words. This is the so-called "vector space model" or bag-of-words representation (Salton et al., 1975). Ignoring case we count the words in each abstract and set the element $x_{n q}$ to the number of times the $q$ th word occurs in the $n$th abstract. Words that only occur in a single abstract are discarded from the matrix and certain stop words are eliminated resulting in a matrix with fewer columns. The stop words are a compound list consisting of ordinary English words such as "the", "of" augmented with medical stop words used in MEDLINE/PubMed (http://www.ncbi.nlm.nih.gov/entrez/query/static/help/pmhelp.html\#Stopwords) and by a large manually constructed list for elimination of words that does not directly describe cognitive functions, e.g., words for brain anatomy are eliminated.

A number of methods for discovering latent classes ("clusters" or "components") in texts have been described, e.g., spherical K-means and singular value decomposition (SVD) (Dhillon and Modha, 2001), simple counting (Goldman et al., 1999), Probabilistic Latent Semantic Analysis (PLSA) (Hofmann, 1999), hierarchical clustering (Gaussier et al., 2002), non-negative matrix factorization (NMF) (Lee and Seung, 1999), Generalizable Gaussian Mixture (GGM) model (Hansen et al., 2000), and independent component analysis (ICA) (Isbell Jr. and Viola, 1999; Kolenda et al., 2000). Some of these have been applied for data mining medical literature (Dobrokhotov et al., 2003; Goldman et al., 1999), and, e.g., the XplorMed Internet-based tool enables interactive exploration of noun relatedness in PubMed abstracts producing simple two-word classes (PerezIratxeta et al., 2001). In our case we will use the NMF with an optimization algorithm for the Euclidean distance cost function (Lee and Seung, 2001) where a matrix $\mathbf{X}(N \times Q)$ is factorized into two non-negative matrices $\mathbf{W}(N \times K)$ and $\mathbf{H}(K \times P)$

$$
\mathbf{X}=\mathbf{W H}+\mathbf{E},
$$

and the cost function (reconstruction error) $E$ is defined as

$$
E=\operatorname{trace}\left(\mathbf{E E}^{\top}\right)=\operatorname{trace}\left(\mathbf{E}^{\top} \mathbf{E}\right)=\|\mathbf{E}\|_{F}^{2},
$$

This cost function is minimized for a fixed number of latent classes $K$. Each of the column vectors in $\mathbf{W}$ corresponds to a latent class with loadings for each abstract, and each of the rows in $\mathbf{H}$ contains a latent class with loadings over words. The algorithm is dependent on the initialization of $\mathbf{W}$ and $\mathbf{H}$. To avoid unfavorable local minima we run the algorithm multiple times and choose the result with the lowest cost function value. NMF has the advantage that each vector (in either $\mathbf{W}$ or $\mathbf{H}$ ) corresponds to one latent class. In SVD and (ordinary) ICA there might be two classes in each vector, since the algorithms implicitly assume a symmetric distribution around zero, for an example see (Kleinberg, 1999). SVD further requires that the relevant loading vectors are orthogonal. ICA requires either loadings over abstracts or loadings over words to be statistically independent. Furthermore, NMF produces sparse components that are intuitively more suitable for text than the holistic components from SVD analysis (Lee and Seung, 1999). The mathematical uniqueness of NMF is a topic of current research see, e.g., (Donoho and Stodden, 2004). In hard 
assigning clustering algorithms such as K-means we only get an indicator for membership. In NMF we get a continuous value for "more or less membership" to the latent class which means that we are able to sort both the elements of $\mathbf{W}$ and $\mathbf{H}$ and report the top most representative abstract and words associated with each class.

The number of latent classes $K$ in NMF is the only parameter that needs to be set. In cluster analysis we have previously determined an optimal number of classes by information criteria or cross-validation (Goutte et al., 1999; Goutte et al., 2001; Balslev et al., 2002). Here, we will instead run the algorithm over different numbers of classes and use a visualization technique to get an overview of the structures in the data: We plot the classes as nodes in a 2-dimensional plot with $K$ on the $y$-axis and the individual classes $k=1 \ldots K$ on the $x$-axis. Thus each row represents one run of NMF with a specific number of classes, e.g., the 5 th row is for $K=5$. On each node we print the words with the highest load in the classes of $\mathbf{H}$. These words represents the most typical words for the class. Nodes in adjacent layers (between $K$ and $K+1$ ) are connected with lines and the thickness of these lines is determined from the similarity between the classes. The similarity between the $k$ th class in a $K$-class NMF and the $k^{\prime}$ th class in a $(K+1)$-class NMF is computed as the inner product between the corresponding latent class vectors

$$
s_{k, k^{\prime}}=\left(\mathbf{w}_{k}^{K}\right)^{\top} \mathbf{w}_{k^{\prime}}^{K+1}
$$

Only the lines where the similarity is high are shown. A threshold $c$ was found as

$$
s_{k, k^{\prime}} / \max _{k, k^{\prime}} s_{k, k^{\prime}}>c,
$$

where a useful value for $c$ was found in the range $0.05-0.15$.

The text mining described above allows us to identify sub-categories in connection with PCC. In our second step we use spatial modeling to further characterize each of these sub-categories in terms of distribution in Talairach space (Fox et al., 2001). For each class $k$ the loadings on abstracts in $\tilde{\mathbf{w}}_{k}$ are sorted and the Talairach coordinates from the top twenty abstracts are plotted. We only take the coordinates from abstracts that are "winners" of each class by a applying a "winner-take-all" function $\tilde{\mathbf{W}}=\operatorname{wta}(\mathbf{W})$ with the elements determined as

$$
\tilde{w}_{n k}= \begin{cases}w_{n k} & \text { if } \forall_{k^{\prime}}: w_{n k} \geq w_{n k^{\prime}} \\ 0 & \text { otherwise. }\end{cases}
$$

The coordinates were extracted from the Brede database (Nielsen, 2003) or, if not available in this database, typed in manually. We compare the distributions of Talairach coordinates from two classes by statistical tests (Berman et al., 1999; Christoff and Grabrieli, 2000; Duncan and Owen, 2000). The coordinates from the two classes are represented in two data matrices $\mathbf{Z}_{1}\left(M_{1} \times 3\right)$ and $\mathbf{Z}_{2}\left(M_{2} \times 3\right)$ and the two-sample Hotelling $T^{2}$ statistical test is applied where a scaled sample Mahalanobis distance follows an $F$-distribution if independent multivariate Gaussian distributions are assumed (Mardia et al., 1979, p. 77)

$$
\frac{M_{1} M_{2}(M-P-1)}{M(M-2) P} D^{2} \sim F_{P, M-P-1} .
$$

The Mahalanobis distance is computed as

$$
D^{2}=\left(\overline{\mathbf{z}}_{1}-\overline{\mathbf{z}}_{2}\right)^{\top} \mathbf{S}_{u}^{-1}\left(\overline{\mathbf{z}}_{1}-\overline{\mathbf{z}}_{2}\right),
$$

with the covariance $\mathbf{S}_{u}$ found as

$$
\mathbf{S}_{u}=\left(M_{1} \mathbf{S}_{1}+M_{2} \mathbf{S}_{2}\right) /(M-2),
$$


where $M=M_{1}+M_{2}, \overline{\mathbf{z}}_{1}$ and $\overline{\mathbf{z}}_{2}$ are the means for the two sets of Talairach coordinates and $\mathbf{S}_{1}$ and $\mathbf{S}_{2}$ are the biased covariance maximum likelihood estimates, e.g., $\mathbf{S}_{1}=\mathbf{Z}_{1}^{\top} \mathbf{Z}_{1} / M_{1}-\overline{\mathbf{z}}_{1}^{\top} \overline{\mathbf{z}}_{1} . P$ is the dimension of the space, i.e., $P=3$ if the test is applied in the full 3-dimensional Talairach space. Taking a pluralistic approach to modeling (Lange et al., 1999), and since the distributions seem mildly non-Gaussian we also consider a permutation test on the Euclidean, median and Mahalanobis distances between the two sets of coordinates (Mardia, 1970; Edgington, 1986; Arnold et al., 1997). Permutation on the Mahalanobis distance will correspond to a permutation test on the Hotelling $T^{2}$ statistics since there is only a scaling difference between the Mahalanobis distance and the Hotelling $T^{2}$, cf. equation 6 . The median test is only applied in one dimension.

The stop word lists and the tools for the analysis are available in the Brede neuroinformatics toolbox (Nielsen and Hansen, 2000) presently available from http://hendrix.imm.dtu.dk/software/brede/.

\section{Results}

PubMed returned 271 items matching the query on PCC and imaging on the date 2003-08-14. After the abstracts had been converted to vectorial form and single occurrence words and stop words were eliminated 549 words remained from originally 4792 , resulting in the data matrix $\mathbf{X}(271 \times 549)$. "Memory", "alzheimer", "visual", "metabolic", "retrieval" and "pain" showed up as the most frequent occurring words. "Memory" occurred twice as often compared to the second most frequent word.

Figure 2 shows the automatically generated "NMF tree" where each of the yellow nodes indicates a NMF component. These are labeled with the words with the highest score in $\mathbf{H}$. Although the particular configuration of the NMF tree changes when the algorithm is restarted, the major themes are invariant over runs. The tree with the root in $(1,1)$ shows that memory is a dominant theme throughout the hierarchy $(K=1 \ldots 12)$. The words showing the highest association with the component are "memory", "retrieval" and "episodic". An automatically generated list of articles scoring high on the "memory" component $\tilde{\mathbf{w}}_{k=\text { memory }}$ is available in table 1.

Other important themes are Alzheimer's disease with mild cognitive impairment (represented by words such as "alzheimer", "metabolic", "mci", "dementia") and pain ("painful", "nonpainful", "somatosensory", "sensation", "heat"). Table 2 lists the abstracts associated with the pain component. Furthermore, a "sensorimotor" component is associated with words such as "hand", "motor", "visual" and "reaching" but only a few functional studies support this theme (Kertzman et al., 1997; Inoue et al., 1998). A component associated with Posttraumatic Stress Syndrome (PTSD) is dominated by a few abstracts by J. D. Bremner (Bremner et al., 1999b; Bremner et al., 1999a; Bremner, 2002; Bremner et al., 2003). Other components also showed to be dominated by a single author. This is the case for the visual motion component (Cornette et al., 1998) and the associative learning component (Hunkin et al., 2002). A final component contains emotion, familiarity and facial expression perception. We will refer to this as the "emotion" component even though only about half the abstracts were genuine emotion studies. The associated abstracts are listed in table 3 .

Most of the articles displayed in the tables 1, 2 and 3 listed Talairach coordinates. We extracted PCC coordinates from these articles even though some of the entries were not strictly associated with the main theme of the component, e.g., a taste study (Gautier et al., 1999) appears in the pain component. A coordinate marked "Left posterior cingulate/precuneus" (Boxer et al., 2003) was left out since it was too posterior $(y=-96)$ to be in PCC. An other outlier left out was "right postcentral gyrus/posterior cingulate gyrus" with $x=52$ (Jernigan et al., 1998). Single subjects activations in PCC from a third study (Maddock and Buonocore, 1997) were averaged to one single coordinate. All included studies except one event related potential study (Chen et al., 2002) were either PET or fMRI studies.

Figure 3 displays a sagittal view of the focal brain activation distribution of memory (green 


\begin{tabular}{|c|c|c|c|}
\hline$\#$ & Load & Title & Reference \\
\hline 1 & 7.81 & $\begin{array}{l}\text { Remembering the past: two facets of episodic memory explored } \\
\text { with positron emission tomography. }\end{array}$ & $\begin{array}{l}\text { (Andreasen et al., } \\
1995 \mathrm{~b})\end{array}$ \\
\hline 2 & 7.56 & $\begin{array}{l}\text { Differential remoteness and emotional tone modulate the neural } \\
\text { correlates of autobiographical memory. }\end{array}$ & (Piefke et al., 2003) \\
\hline 3 & 5.74 & $\begin{array}{l}\text { Differential modulation of a common memory retrieval network } \\
\text { revealed by positron emission tomography. }\end{array}$ & $\begin{array}{l}\text { (Maguire and Mum- } \\
\text { mery, 1999) }\end{array}$ \\
\hline 4 & 5.11 & $\begin{array}{l}\text { Remembering familiar people: the posterior cingulate cortex } \\
\text { and autobiographical memory retrieval. }\end{array}$ & (Maddock et al., 2001) \\
\hline 5 & 5.06 & $\begin{array}{l}\text { Neuroanatomical correlates of episodic encoding and retrieval in } \\
\text { young and elderly subjects. }\end{array}$ & (Daselaar et al., 2003) \\
\hline 6 & 4.89 & $\begin{array}{l}\text { Verbal encoding deficits in a patient with a left retrosplenial } \\
\text { lesion. }\end{array}$ & $\begin{array}{l}\text { (McDonald et al., } \\
\text { 2001) }\end{array}$ \\
\hline 7 & 4.73 & $\begin{array}{l}\text { The functional neuroanatomy of episodic memory: the role of } \\
\text { the frontal lobes, the hippocampal formation, and other areas. }\end{array}$ & $\begin{array}{l}\text { (Desgranges et al., } \\
1998)\end{array}$ \\
\hline 8 & 4.57 & $\begin{array}{l}\text { Parietal and hippocampal contribution to topokinetic and topo- } \\
\text { graphic memory. }\end{array}$ & (Berthoz, 1997) \\
\hline 9 & 4.43 & $\begin{array}{l}\text { The effects of bilateral hippocampal damage on fMRI regional } \\
\text { activations and interactions during memory retrieval. }\end{array}$ & (Maguire et al., 2001) \\
\hline 10 & 4.33 & $\begin{array}{l}\text { Network analysis in episodic encoding and retrieval of word-pair } \\
\text { associates: a PET study. }\end{array}$ & (Krause et al., 1999) \\
\hline 11 & 4.21 & $\begin{array}{l}\text { Cerebral representation of one's own past: neural networks in- } \\
\text { volved in autobiographical memory. }\end{array}$ & (Fink et al., 1996) \\
\hline 12 & 3.98 & $\begin{array}{l}\text { Brain regions associated with acquisition and retrieval of verbal } \\
\text { episodic memory. }\end{array}$ & (Shallice et al., 1994) \\
\hline 13 & 3.86 & $\begin{array}{l}\text { The role of the basal forebrain in episodic memory retrieval: a } \\
\text { positron emission tomography study. }\end{array}$ & (Fujii et al., 2002) \\
\hline 14 & 3.49 & $\begin{array}{l}\text { A combined neuropsychological and neuroimaging study of to- } \\
\text { pographical and non-verbal memory in semantic dementia. }\end{array}$ & $\begin{array}{l}\text { (Cipolotti } \\
\text { Maguire, 2003) }\end{array}$ \\
\hline 15 & 3.00 & Changing patterns of brain activation during maze learning. & (Van Horn et al., 1998) \\
\hline 16 & 2.82 & Neural correlates of semantic and episodic memory retrieval. & (Wiggs et al., 1999) \\
\hline 17 & 2.75 & $\begin{array}{l}\text { Network analysis of positron emission tomography regional cere- } \\
\text { bral blood flow data: ensemble inhibition during episodic mem- } \\
\text { ory retrieval. }\end{array}$ & (Nyberg et al., 1996) \\
\hline 18 & 2.71 & $\begin{array}{l}\text { Task-related and item-related brain processes of memory re- } \\
\text { trieval. }\end{array}$ & (Düzel et al., 1999) \\
\hline 19 & 2.66 & $\begin{array}{l}\text { Posterior cingulate cortex activation by emotional words: fMRI } \\
\text { evidence from a valence decision task. }\end{array}$ & (Maddock et al., 2003) \\
\hline 20 & 2.49 & $\begin{array}{l}\text { Neocortical system abnormalities in autism: an fMRI study of } \\
\text { spatial working memory. }\end{array}$ & (Luna et al., 2002) \\
\hline
\end{tabular}

Table 1: Memory class: Abstracts associated with the memory class sorted according to loading, i.e., values in $\tilde{\mathbf{w}}_{k=\text { memory. }}$ For this specific list the $(1,4)$-node from figure 2 was selected. 


\begin{tabular}{|c|c|c|c|}
\hline$\#$ & Load & Title & Reference \\
\hline 1 & 9.87 & $\begin{array}{l}\text { Central representation of chronic ongoing neuropathic pain stud- } \\
\text { ied by positron emission tomography. }\end{array}$ & (Hsieh et al., 1995) \\
\hline 2 & 8.14 & $\begin{array}{l}\text { Regional brain activity changes associated with fentanyl analge- } \\
\text { sia elucidated by positron emission tomography. }\end{array}$ & (Adler et al., 1996) \\
\hline 3 & 7.97 & $\begin{array}{l}\text { Region-specific encoding of sensory and affective components } \\
\text { of pain in the human brain: a positron emission tomography } \\
\text { correlation analysis. }\end{array}$ & (Tölle et al., 1999) \\
\hline 4 & 7.66 & $\begin{array}{l}\text { Central processing of rectal pain: a functional MR imaging } \\
\text { study. }\end{array}$ & (Baciu et al., 1999) \\
\hline 5 & 6.60 & $\begin{array}{l}\text { Phantom limb pain in the human brain: unraveling neural cir- } \\
\text { cuitries of phantom limb sensations using positron emission to- } \\
\text { mography. }\end{array}$ & (Willoch et al., 2000) \\
\hline 6 & 5.70 & $\begin{array}{l}\text { A PET activation study of dynamic mechanical allodynia in } \\
\text { patients with mononeuropathy. }\end{array}$ & (Petrovic et al., 1999) \\
\hline 7 & 5.38 & $\begin{array}{l}\text { A comparative fMRI study of cortical representations for ther- } \\
\text { mal painful, vibrotactile, and motor performance tasks. }\end{array}$ & (Gelnar et al., 1999) \\
\hline 8 & 4.71 & $\begin{array}{l}\text { Spatial summation of pain processing in the human brain as } \\
\text { assessed by cerebral event related potentials. }\end{array}$ & (Chen et al., 2002) \\
\hline 9 & 4.56 & $\begin{array}{l}\text { Pain processing in four regions of human cingulate cortex local- } \\
\text { ized with co-registered PET and MR imaging. }\end{array}$ & (Vogt et al., 1996) \\
\hline 10 & 4.45 & $\begin{array}{l}\text { Functional MR imaging analysis of pain-related brain activation } \\
\text { after acute mechanical stimulation. }\end{array}$ & (Creac'h et al., 2000) \\
\hline 11 & 4.27 & Central nervous pathways mediating angina pectoris. & (Rosen et al., 1994) \\
\hline 12 & 2.15 & Cerebral mechanisms of hypnotic induction and suggestion. & (Rainville et al., 1999) \\
\hline 13 & 1.88 & $\begin{array}{l}\text { Neuroimmune relations in patients with fibromyalgia: a positron } \\
\text { emission tomography study. }\end{array}$ & (Lekander et al., 2000) \\
\hline 14 & 1.44 & $\begin{array}{l}\text { Human brain activation under controlled thermal stimulation } \\
\text { and habituation to noxious heat: an fMRI study. }\end{array}$ & (Becerra et al., 1999) \\
\hline 15 & 1.01 & $\begin{array}{l}\text { Central representation of visceral and cutaneous hypersensitiv- } \\
\text { ity in the irritable bowel syndrome. }\end{array}$ & (Verne et al., 2003) \\
\hline 16 & 0.97 & $\begin{array}{l}\text { Anatomical localization and intra-subject reproducibility of } \\
\text { laser evoked potential source in cingulate cortex, using a re- } \\
\text { alistic head model. }\end{array}$ & (Bentley et al., 2002) \\
\hline 17 & 0.88 & Brain images of pain. & (Bromm, 2001) \\
\hline 18 & 0.39 & $\begin{array}{l}\text { Regions of the human brain affected during a liquid-meal taste } \\
\text { perception in the fasting state: a positron emission tomography } \\
\text { study. }\end{array}$ & (Gautier et al., 1999) \\
\hline 19 & 0.37 & fMRI of the responses to vibratory stimulation of digit tips. & (Francis et al., 2000) \\
\hline 20 & 0.36 & $\begin{array}{l}\text { Cerebral activation in patients with irritable bowel syndrome } \\
\text { and control subjects during rectosigmoid stimulation. }\end{array}$ & (Naliboff et al., 2001) \\
\hline
\end{tabular}

Table 2: Pain class: Abstracts associated with the pain class sorted according to loading, i.e., values in $\tilde{\mathbf{w}}_{k=\text { pain. }}$ For this specific list the $(3,4)$-node from figure 2 was selected. 


\begin{tabular}{|c|c|c|c|}
\hline \# & Load & Title & Reference \\
\hline 1 & 14.15 & $\begin{array}{l}\text { Investigation of facial recognition memory and happy and sad } \\
\text { facial expression perception: an fMRI study. }\end{array}$ & (Phillips et al., 1998) \\
\hline 2 & 11.60 & $\begin{array}{l}\text { Ketamine alters neural processing of facial emotion recognition } \\
\text { in healthy men: an fMRI study. }\end{array}$ & (Abel et al., 2003) \\
\hline 3 & 7.60 & $\begin{array}{l}\text { Posterior cingulate cortex activation by emotional words: fMRI } \\
\text { evidence from a valence decision task. }\end{array}$ & (Maddock et al., 2003) \\
\hline 4 & 4.79 & $\begin{array}{l}\text { The neural correlates of person familiarity. A functional mag- } \\
\text { netic resonance imaging study with clinical implications. }\end{array}$ & (Shah et al., 2001) \\
\hline 5 & 4.76 & Dissociable prefrontal brain systems for attention and emotion. & (Yamasaki et al., 2002) \\
\hline 6 & 2.66 & $\begin{array}{l}\text { Cerebral blood flow in subjects with social phobia during stress- } \\
\text { ful speaking tasks: a PET study. }\end{array}$ & (Tillfors et al., 2001) \\
\hline 7 & 2.56 & $\begin{array}{l}\text { Functional neuroanatomy of visually elicited simple phobic fear: } \\
\text { additional data and theoretical analysis. }\end{array}$ & $\begin{array}{l}\text { (Fredrikson et al., } \\
\text { 1995) }\end{array}$ \\
\hline 8 & 2.39 & $\begin{array}{l}\text { Activation of left posterior cingulate gyrus by the auditory pre- } \\
\text { sentation of threat-related words: an fMRI study. }\end{array}$ & $\begin{array}{l}\text { (Maddock and Buono- } \\
\text { core, 1997) }\end{array}$ \\
\hline 9 & 2.20 & Cerebral blood flow during anxiety provocation. & $\begin{array}{l}\text { (Fredrikson et al., } \\
\text { 1997) }\end{array}$ \\
\hline 10 & 1.82 & A functional cerebral response to frightening visual stimulation. & (Wik et al., 1993) \\
\hline 11 & 1.29 & $\begin{array}{l}\text { Cortical networks recruited for time perception: a monkey } \\
\text { positron emission tomography (PET) study. }\end{array}$ & (Onoe et al., 2001) \\
\hline 12 & 1.22 & $\begin{array}{l}\text { Investigating the functional anatomy of empathy and forgive- } \\
\text { ness. }\end{array}$ & (Farrow et al., 2001) \\
\hline 13 & 1.17 & Neural substrates for the perception of acutely induced dyspnea. & (Peiffer et al., 2001) \\
\hline 14 & 1.05 & $\begin{array}{l}\text { Brain abnormalities in early-onset schizophrenia spectrum dis- } \\
\text { order observed with statistical parametric mapping of structural } \\
\text { magnetic resonance images. }\end{array}$ & (Sowell et al., 2000) \\
\hline 15 & 1.02 & The neural basis of romantic love. & $\begin{array}{l}\text { (Bartels and Zeki, } \\
2000)\end{array}$ \\
\hline 16 & 0.97 & $\begin{array}{l}\text { The posterior cingulate and medial prefrontal cortex mediate } \\
\text { the anticipatory allocation of spatial attention. }\end{array}$ & (Small et al., 2003) \\
\hline 17 & 0.84 & Focal gray matter density changes in schizophrenia. & $\begin{array}{l}\text { (Hulshoff Pol et al., } \\
\text { 2001) }\end{array}$ \\
\hline 18 & 0.77 & $\begin{array}{l}\text { Neural basis of the Stroop interference task: response competi- } \\
\text { tion or selective attention? }\end{array}$ & (Mead et al., 2002) \\
\hline 19 & 0.73 & $\begin{array}{l}\text { Functional magnetic resonance imaging of human visual cortex } \\
\text { during face matching: a comparison with positron emission to- } \\
\text { mography. }\end{array}$ & (Clark et al., 1996) \\
\hline 20 & 0.53 & $\begin{array}{l}\text { 6-(18)F-DOPA PET study in patients with schizophrenia. } \\
\text { Positron emission tomography. }\end{array}$ & (Elkashef et al., 2000) \\
\hline
\end{tabular}

Table 3: Emotion class: Abstracts associated with the Emotion class sorted according to loading,

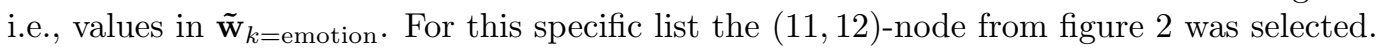




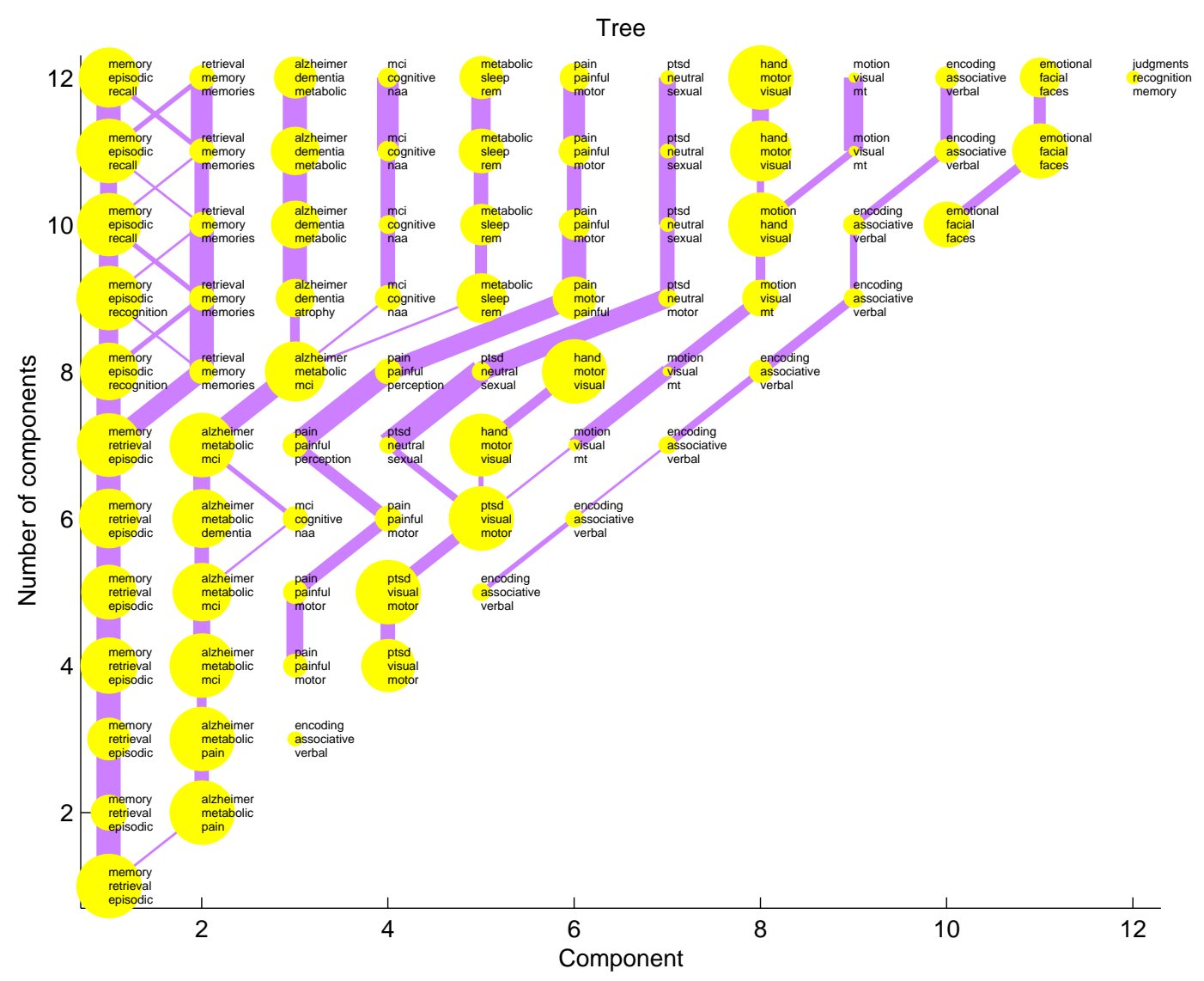

Figure 2: NMF tree with components from non-negative matrix factorization of the bag-of-words converted posterior cingulate abstracts. The nodes indicated by yellow dots represent each a specific component $k \in\{1 \ldots K\}$ for a specific $K$. The $y$-axis is indicating a specific number of classes $K$. The size of the dots indicates the fraction of documents assigned to the component. The lines indicate the similarity between components, see equations 3 and 4 in the text.

squares) and pain (red triangles) extracted from the most salient articles of the two most prominent components from the NMF analysis. The gray outline is an isocurvature in a probability volume for PCC based on modeling of all coordinates from the Brede database labeled either "posterior cingulate" or "retrosplenial" (Nielsen and Hansen, 2002). A clear difference is seen between the two with memory brain activations primarily in the caudal part of PCC while the pain brain activations are mostly confined to the rostral or superior part of PCC. Two of the pain activations in the caudal part are actually from the taste study (Gautier et al., 1999).

The statistical tests for difference in distributions between memory and pain coordinates showed a large segregation with $P$-values around $P \approx 0.002$ for both Hotelling's $T^{2}$ test and the Mahalanobis permutation test while the permutation test on the Euclidean distance was somewhat lower $(P \approx 0.0004)$. If the test was restricted to the sagittal coordinates $(y$ and $z)$ the $P$-values were lower, e.g., Hotelling $T^{2}$ test $P$-value for the coordinates from articles listed in tables 1 and 2 was $P=0.000658$ and $P \approx 0.0003$ for the mean permutation test. Statistical tests also gave evidence for a separation between memory and Alzheimer with $P \approx 0.01\left(P_{T^{2}, 3 \mathrm{D}}=0.0172\right.$, 


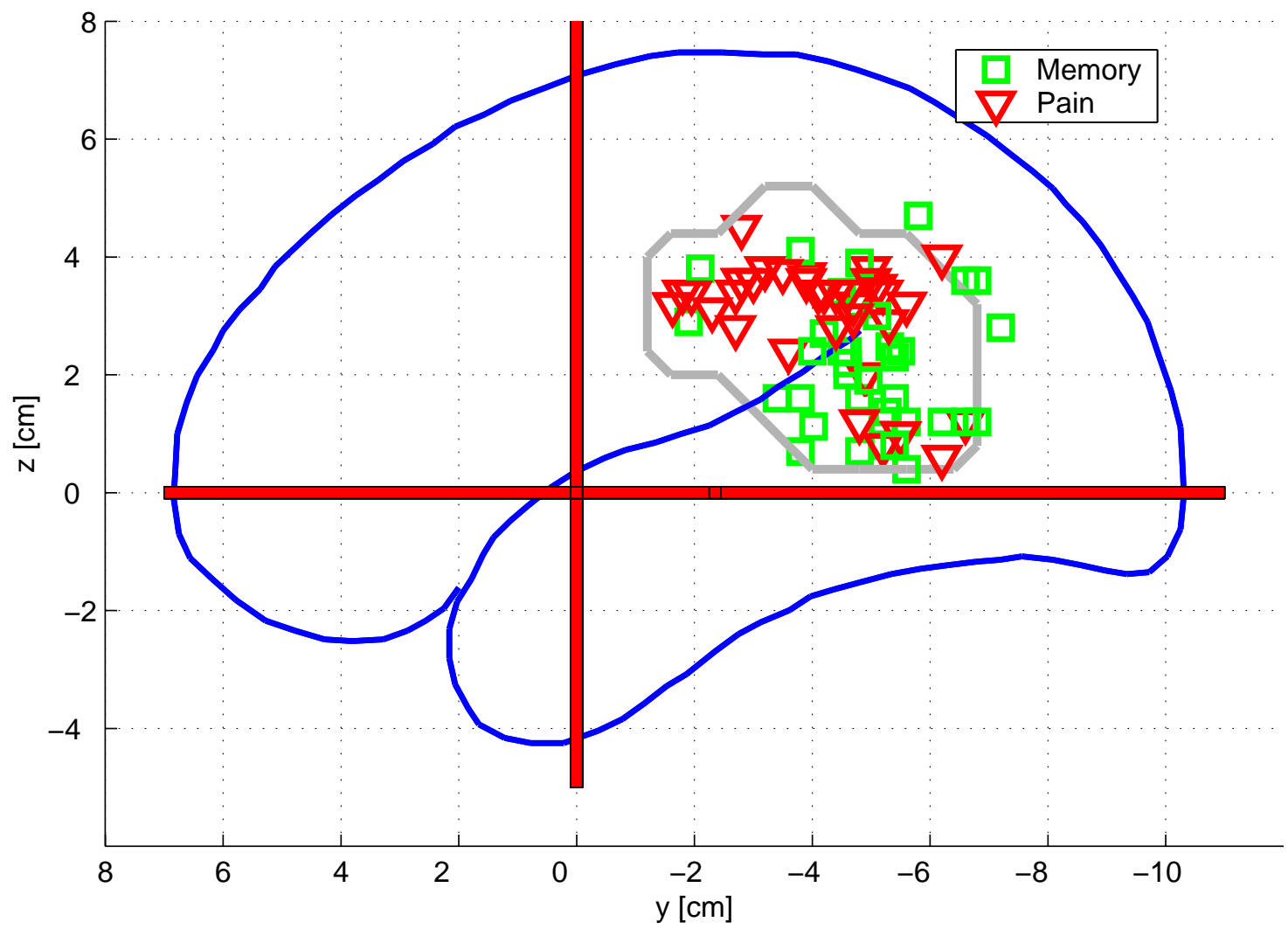

Figure 3: Distribution of memory and pain brain activations in the posterior cingulate cortex shown on a sagittal plot: $y$ is the AP-axis with posterior as negative. The blue outline follows that of the Talairach atlas. The gray outline is an isocurvature in a probability volume for posterior cingulate cortex based on modeling of coordinates from the Brede database. Green squares are associated with "memory" articles and red triangles with "pain" articles.

$P_{T^{2}}$, Sagittal $=0.0098, P_{\text {Maha. }}$ Perm., Sagittal $\left.\approx 0.008\right)$. The ordinary tests show very little difference between pain and Alzheimer $P>0.5$, although this might be due to outliers in the Alzheimer set: Many Alzheimer coordinates lay inferior to pain coordinates, while only a few is positioned superior. A permutation test on the median on the Talairach $z$-coordinate showed a clear separation $(P \approx 0.001)$. Statistical testing between memory and emotion showed a very high $P$-value $P>0.5$. There were not much difference between the Hotelling $T^{2}$ and permutation test for any of the tests.

There were few abstracts assigned to the PTSD components. Only 8 coordinates were contained in this components and furthermore were genuine PTSD articles (Bremner et al., 1999a; Bremner et al., 1999b; Pissiota et al., 2002; Bremner et al., 2003). These showed to be mostly distributed in the rostral part of PCC and with the two most caudal brain activations actually being deactivations in relation to PTSD provocation (Pissiota et al., 2002). This could give evidence for PTSD activation to be confined to the rostral part. To investigate this further we augmented the set with additional coordinates mentioned in a recent review (Bremner, 2002; Shin et al., 1997; Shin et al., 1999; Lanius et al., 2001), and we divided them into "positive" and "negative" PTSD activations, see figure 4 . These new coordinates did not support the hypothesis since they were distributed across the entire PCC. 


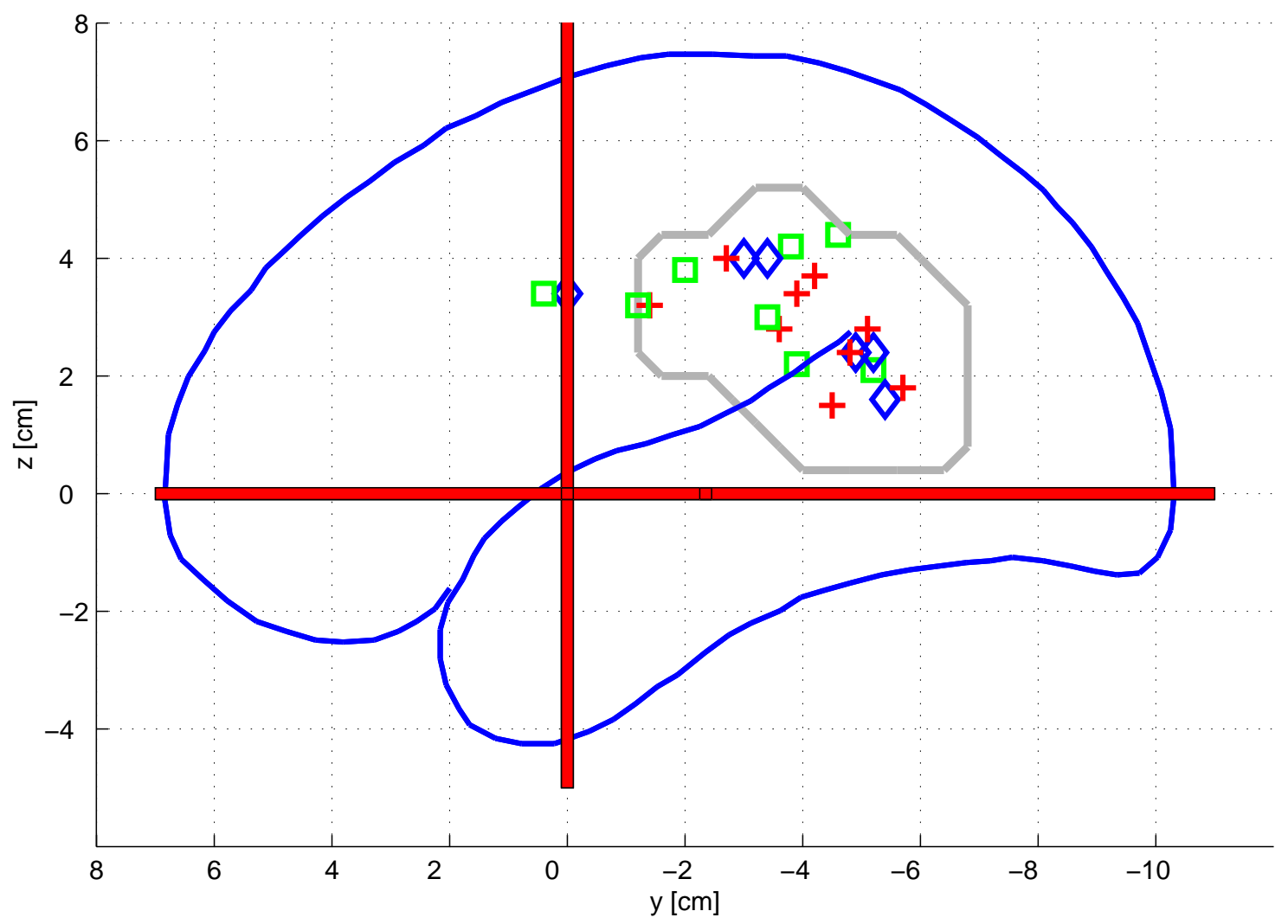

Figure 4: Distribution of PTSD brain activations. Green squares are from our initial set while red pluses and blue diamond are "positive" and "negative" PTSD activations from an extra set of articles.

\section{Discussion}

We find the most prominent component to be associated with words such as "memory", "retrieval" and "episodic". This is in alignment with a major review that associates PCC with successful episodic memory retrieval (Cabeza and Nyberg, 2000). The important role of the caudal posterior cingulate cortex in successful autobiographical memory retrieval has previously been noted (Maddock et al., 2001), and this is also in very well alignment with our finding of the spatial distribution of memory activations, although our results does not emphasize the success and autobiographical content, but rather general episodic memory retrieval.

Our finding of Alzheimer's Disease and Mild Cognitive Impairment as an important theme is also in agreement with findings of the neuroimaging literature where PCC hypometabolism is prevalent, see, e.g., (Minoshima et al., 1994; Volkow et al., 2002; Nybäck et al., 1991).

The large contribution from pain in PCC studies is surprising: Pain activation has especially been associated with the anterior or middle part of cingulate cortex (Brodmann areas 24/32) (Vogt et al., 1992; Ingvar, 1999; Peyron et al., 2000), seldom posterior to Talairach coordinate $y=-2 \mathrm{~cm}$. Magneto- and encephalography results have suggested involvement of the posterior cingulate area (Bromm, 2001), e.g., a study estimated a laser evoked potential dipole source to be at the border between the anterior and posterior cingulate cortex in the left hemisphere (Bentley et al., 2002). Our results suggest that a larger part of cingulate cortex than just anterior cortex is associated with pain. Furthermore, this pain component has a focus that is shifted compared to the focus of 
the memory component: All statistical test identify a differentiation between the memory and pain components and simple visual inspection of figure 3 also testifies to this. Our analysis does not enables us to say whether specific sub-components of pain (such as affective, sensory or cognitive) are especially pronounced in PCC, and if the PCC contribution to pain might be a part of the stronger activation in the anterior cingulate cortex. Our differentiation between the pain and the memory components appears along a rostrocaudal axis while standard cytoarchitectonic areas have a "ventrodorsal" order with Brodmann areas 29, 30, 23, 31 (Vogt et al., 2001). Cytoarchitectonic rostrocaudal differentiation has been made in Macaca fascicularis with the definition of 23e, 23i and $23 \mathrm{v}$, where 23v is the most caudal (Kobayashi and Amaral, 2000), and differences in thalamic connection have been found between the posteroventral (caudal) and dorsal regions of area 23b in Macaca fuscata (Shibata and Yukie, 2003). However, it is not clear whether these differences relate to the functional differentiation we find.

Emotion has been associated with PCC and a review concludes that "the retrosplenial cortex is the cortical region that is most consistently activated by the emotional salience of experimental stimuli" (Maddock, 1999), where "retrosplenial" here means the most-caudal part of PCC (Vogt et al., 2000; Vogt et al., 2001). Apart from articles mentioned by the review (Maddock, 1999) PCC has been associated with emotion in, e.g., facial anger viewing (Sprengelmeyer et al., 1998), facial happiness viewing (Phillips et al., 1998; Kilts et al., 1996), visual elicited phobic fear (Fredrikson et al., 1995) and romantic love (Bartels and Zeki, 2000). A single component contains a number of these emotion studies, but the component is not very "clean" in the sense that it does not exclusively contain emotion studies, so we can only leniently conclude that there is a tendency for overlap between the emotion and the memory in the spatial distribution in Talairach space and it appears in caudal PCC.

Measurements in several species indicate that PCC is implicated in eye movements (Vogt et al., 1992; Olson et al., 1996), and functional neuroimaging in humans identify PCC activation in saccades and pursuit tracking (Berman et al., 1999). One could expect to find a component corresponding to eye movement, but this did not appear as a major theme in our analysis of functional neuroimaging studies.

A missing theme in our analysis is navigation and spatial orientation: The involvement of PCC in navigation is supported by ten case studies with patients showing topographical disorientation as the primary deficit (Maguire, 2001). Furthermore, a number of animal lesion and electrophysiological studies have shown that PCC contributes to "spatial orientation" (Vogt et al., 1992). Human retrosplenial activation has also been reported in an allocentric environment-based task which required no real or virtual locomotion (Committeri et al., 2003). The reason why a navigation component does not show up is probably due to that some of the fMRI and PET navigation studies do not mention PCC (including retrosplenial cortex) in the title or abstract even when changes in this area are in fact reported: Eight of the 11 PET or fMRI studies listed in a review of retrosplenial cortex in navigation (Maguire, 2001) do not mention PCC. Another study is excluded from our analysis because "magnetic resonance imaging" is neither mentioned in the abstract nor indexed in the MeSH terms by PubMed (only "MRI" is mentioned in the abstract) (Grön et al., 2000). Two studies included in our analysis (Burgess et al., 2001; Ghaem et al., 1997) show high loading on the "memory" component which might be a suitable categorization since these "navigation" studies investigated retrieval of the spatial context and "memorized routes". The few navigation studies are not able to generate their own component. The same problem applies for the few studies contrasting "resting state" (where the subjects have been instructed to close their eyes) with a number of diverse activation states finding posterior cingulate or nearby precuneus activation (Shulman et al., 1997; Mazoyer et al., 2001; Raichle et al., 2001; Andreasen et al., 1995a; Binder et al., 1999). Of these only two are included (Mazoyer et al., 2001; Andreasen et al., 1995a) both primarily classified as "memory", the major theme of the latter.

The bag-of-words approach although a crude representation of written narrative, has proved to be able to identify themes that appear meaningful and aligned with "human powered" metaanalysis. The simple representation is however not able to identify in which local context the 
words appear. We used a large stop word list to discard frequent words with little reference to cognitive function. More advanced feature extraction algorithms would invoked more advanced phrase structure and natural language processing which has proven to give superior results in question/answering information retrieval tasks (Pasca and Harabagiu, 2001).

We did not intend to find all articles that are relevant for PCC. Many articles that report PCC activation do not mention the area in the abstract, and furthermore, our specific query with search on a limited number of words does not capture all relevant articles. Yet, our presently available data base do yield sensible results, and serves as proof of concept for future extensive datamining investigations. As databases such as BrainMap DBJ (Fox and Lancaster, 2002) and Brede (Nielsen, 2003) increase in scope this will further the successful retrieval of relevant articles and indeed our method can be implemented as an integrated part of services offered in connection with these databases, as it is the case with "related volumes" services already in operation (Nielsen and Hansen, 2004). Increasing availability of electronic full text articles on the Internet will also assist the identification of relevant research.

Comparison with the permutation test on the Mahalanobis distance showed that the parametric Hotelling $T^{2}$ two-sample test is not very much affected by mild non-Gaussianity. However, the two test are probably not unbiased: The tests assume independent distributed or "exchangeable" activations and this is probably not true since there might be "intra-author" and "intra-study" effects that violate the independence assumption and activations within an article is not independent. These effects are hard to model or access. However, our investigation of memory and pain brain activation is based on a large number of mostly independent studies, so the overall conclusion should not be affected.

Another bias arises since the individual abstracts can probably not be regarded as fully independent and identically distributed: Dominant authors or laboratories might tend to use a stereotypical vocabulary. We have inspected the tables to explore for this effect but did not find obvious examples.

Our present method use the frequency of words as the features. A number of other weighting schemes have been suggested in the information retrieval literature see, e.g, (Salton and Buckley, 1988), and these have an effect on the NMF components. We choose to use the frequency of words because of the simplicity and the emphasis it will put on the high frequency themes. However, some components can be dominated by single abstracts. In most cases this effect is unwanted and future work will be devoted to develop weighting schemes where these effects can be controlled.

The limited resolution of functional neuroimaging along with differences in brain templates and image registration procedures as well as spatial filtering during analysis and variation in the way the Talairach coordinates are found will probably make it difficult to localize the precise area, e.g., in terms of cytoarchitecture. Our analysis shows that the Talairach coordinates has an advantage over lobar anatomy: Talairach coordinates allow for more precise delineation of an area than the lobar anatomy terminology typically employed.

It should be noted that the "anterior cingulate" and "posterior cingulate" are not well defined areas anatomically, e.g., PCC can be taken to mean only the Brodmann areas 23 and 31. A midcingulate area can be defined (Tzourio-Mazoyer et al., 2002) which means that the area referred to as posterior cingulate will be confined to the caudal region. In this work we have used the ostensive definition in articles and simply taken PCC to mean what is referred to as posterior cingulate and retrosplenial. Our analysis is not affected by this difference unless a part of the functional neuroimaging community, e.g., those involved in "memory", tend to use "mid-cingulate" for the rostral part of posterior cingulate while others, e.g., pain researchers, tend to use "posterior cingulate". 


\section{Conclusion}

We have presented a method for discovering major themes for a specific brain area. Apart from the manual entering of Talairach coordinates our method can be completely automatized.

Our method is not confined to the analysis of the posterior cingulate but can be applied to other brain regions or other words and phrases and their relation to brain anatomy can be identified.

We have found functional heterogeneity in posterior cingulate cortex and the finding of the association between pain and the rostral part of the PCC shows the essence of data mining and knowledge discovery where previously overlooked small correlations become evident when information is aggregated and analyzed.

\section{Acknowledgment}

Finn Årup Nielsen is funded by the Villum Kann Rasmussen Foundation. Daniela Balslev is funded by Copenhagen University Hospital, Rigshospitalet.

\section{References}

Abel, K. M., Allin, M. P. G., Kucharska-Pietura, K., David, A., Andrew, C., Williams, S., Brammer, M. J., and Phillips, M. L. (2003). Ketamine alters neural processing of facial emotion recognition in healthy men: an fMRI study. NeuroReport, 14(3):387-391. PMID: 12634489. DOI: 10.1097/01.wnr.0000058031.29600.31. ISSN 0959-4965.

Adler, L. J., Gyulai, F. E., Diehl, D. J., Mintun, M. A., Winter, P. M., and Firestone, L. L. (1996). Regional brain activity changes associated with fentanyl analgesia elucidated by positron emission tomography. Anesthesia \&3 Analgesia, 84(1):120-126. PMID: 8989012. WOBIB: 101.

Andreasen, N. C., O'Leary, D. S., Cizadlo, T., Arndt, S., Rezai, K., Watkins, G. L., Ponto, L. L., and Hichwa, R. D. (1995a). II. PET studies of memory: novel versus practiced free recall of word lists. NeuroImage, 2(4):296-305. PMID: 9343614. WOBIB: 85. ISSN 1053-8119.

Andreasen, N. C., O'Leary, D. S., Cizadlo, T., Arndt, S., Rezai, K., Watkins, G. L., Ponto, L. L. B., and Hichwa, R. D. (1995b). Remembering the past: two facets of episodic memory explored with positron emission tomography. American Journal of Psychiatry, 152(11):15761585. PMID: 7485619.

Arnold, J. T., Daw, N. C., Stenberg, P. E., Jayawardene, D., Srivastava, D. K., and Jackson, C. W. (1997). A single injection of pegylated murine megakaryocyte growth and development factor (MGDF) into mice is sufficient to produce a profound stimulation of megakaryocyte frequency, size, and ploidization. Blood, 89(3):823-833. http://www.bloodjournal.org/cgi/content/full/89/3/823.

Baciu, M. V., Bonaz, B. L., Papillon, E., Bost, R. A., Bas, J.-F. L., Fournet, J., and Segebarth, C. M. (1999). Central processing of rectal pain: a functional MR imaging study. American Journal of Neuroradiology, 20(10):1920-1924. PMID: 10588119. http://www.ajnr.org/cgi/content/abstract/20/10/1920. ISSN 0195-6108. An fMRI study with a ballon in the rectum of the subjects. There are no Talairach coordinates.

Balslev, D., Nielsen, F. Å., Frutiger, S. A., Sidtis, J. J., Christiansen, T. B., Svarer, C., Strother, S. C., Rottenberg, D. A., Hansen, L. K., Paulson, O. B., and Law, I. (2002). Cluster analysis of activity-time series in motor learning. Human Brain Mapping, 15(3):135-145. http://www3.interscience.wiley.com/cgi-bin/abstract/89011762/. ISSN 1097-0193. 
Bartels, A. and Zeki, S. (2000). The neural basis of romantic love. NeuroReport, 11(17):3829-3834. PMID: 11117499. WOBIB: 54. http://www.vislab.ucl.ac.uk/pdf/NeuralBasisOfLove.pdf.

Becerra, L. R., Breiter, H. C., Stojanovic, M., Fishman, S., Edwards, A., Comite, A. R., Gonzalez, R. G., and Borsook, D. (1999). Human brain activation under controlled thermal stimulation and habituation to noxious heat: An fMRI study. Magnetic Resonance in Medicine, 41(5):1044-1057. PMID: 10332889. WOBIB: 72. http://www3.interscience.wiley.com/cgibin/abstract/61007483/. ISSN 0740-3194.

Bentley, D. E., Youell, P. D., and Jones, A. K. P. (2002). Anatomical localization and intrasubject reproducibility of laser evoked potential source in cingulate cortex, using a realistic head model. Clinical Neurophysiology, 113(8):1351-1356. PMID: 12140016. ISSN 1388-2457.

Berman, R. A., Colby, C. L., Genovese, C. R., Voyvodic, J. T., Luna, B., Thulborn, K. R., and Sweeney, J. A. (1999). Cortical networks subserving pursuit and saccadic eye movements in humans: an FMRI study. Human Brain Mapping, 8(4):209-225. PMID: 10619415. WOBIB: 46. ISSN 1065-9471.

Berthoz, A. (1997). Parietal and hippocampal contribution to topokinetic and topographic memory. Philosophical Transactions of the Royal Society of London. Series B, Biological Sciences, 352(1360):1437-1448. PMID: 9368932. http://links.jstor.org/sici?sici=09628436\%2819971029\%29352\%3A1360\%3C1437\%3APAHCTT\%3E2.0.CO\%3B2-J.

Binder, J. R., Frost, J. A., Hammeke, T. A., Bellgowan, P. S., Rao, S. M., and Cox, R. W. (1999). Conceptual processing during the conscious resting state. a functional MRI study. Journal of Cognitive Neuroscience, 11(1):80-95. PMID: 9950716. WOBIB: 50.

Boxer, A. L., Rankin, K. P., Miller, B. L., Schuff, N., Weiner, M., Gorno-Tempini, M.-L., and Rosen, H. J. (2003). Cinguloparietal atrophy distinguishes Alzheimer disease from semantic dementia. Archives of Neurology, 60(7):949-956. PMID: 12873851. DOI: 10.1001/archneur.60.7.949. ISSN 0003-9942.

Bremner, J. D. (2002). Neuroimaging studies in post-traumatic stress disorder. Current Psychiatry Reports, 4(4):254-263. PMID: 12126593. http://www.current-reports.com/1523-3812/4/254. ISSN 1523-3812.

Bremner, J. D., Narayan, M., Staib, L. H., Southwick, S. M., McGalshan, T., and Charney, D. S. (1999a). Neural correlates of memories of childhood sexual abuse in women with and without posttraumatic stress disorder. American Journal of Psychiatry, 156(11):1787-1795. PMID: 10553744. ISSN 0002-953X.

Bremner, J. D., Staib, L. H., d. Kaloupek, Southwick, S. M., Soufer, R., and Charney, D. S. (1999b). Neural correlates of exposure to traumatic pictures and sound in Vietnam combat veterans with and without posttraumatic stress disorder: a positron emission tomography study. Biological Psychiatry, 45(7):806-816.

Bremner, J. D., Vythilingam, M., Vermetten, E., Southwick, S. M., McGlashan, T., Staib, L. H., Soufer, R., and Charney, D. S. (2003). Neural correlates of declarative memory for emotionally valenced words in women with posttraumatic stress disorder related to early childhood sexual abuse. Biological Psychiatry, 53(10):879-889. PMID: 12742675. ISSN 0006-3223.

Bromm, B. (2001). Brain images of pain. News in Physiological Sciences, 16(5):244-249. PMID: 11572930. http://nips.physiology.org/cgi/content/full/16/5/244.

Burgess, N., Maguire, E. A., Spiers, H. J., and O'Keefe, J. (2001). A temporoparietal and prefrontal network for retrieving the spatial context of lifelike events. NeuroImage, 14(2):439-453. PMID: 11467917. DOI: 10.1006/nimg.2001.0806. ISSN 1053-8119. 
Bush, G., Luu, P., and Posner, M. I. (2000). Cognitive and emotional influences in anterior cingulate cortex. Trends in Cognitive Sciences, 4(6):215-222. PMID: 10827444. http://www.nmr.mgh.harvard.edu/BushLab/Bush_2000_TICS_CingReview.pdf.

Cabeza, R. and Nyberg, L. (2000). Imaging cognition II: An empirical review of 275 PET and fMRI studies. Journal of Cognitive Neuroscience, 12(1):1-47. PMID: 10769304. http://jocn.mitpress.org/cgi/content/abstract/12/1/1.

Chen, A. C. N., Niddam, D. M., Crawford, H. J., Oostenveld, R., and Arendt-Nielsen, L. (2002). Spatial summation of pain processing in the human brain as assessed by cerebral event related potentials. Neuroscience Letters, 328(2):190-194. PMID: 12133585. ISSN 0304-3940.

Christoff, K. and Grabrieli, J. D. E. (2000). The frontopolar cortex and human cognition: Evidence for a rostrocaudal hierarchical organization within the human prefrontal cortex. Psychobiology, 28(2):168-186. http://www-psych.stanford.edu:80/ ${ }^{\sim}$ kalina/papers/psbi2000.pdf. ISSN 08896313.

Cipolotti, L. and Maguire, E. A. (2003). A combined neuropsychological and neuroimaging study of topographical and non-verbal memory in semantic dementia. Neuropsychologia, 41(9):11481159. PMID: 12753955. ISSN 0028-3932.

Clark, V. P., Keil, K., Maisog, J. M., Courtney, S., Ungerleider, L. G., and Haxby, J. V. (1996). Functional magnetic resonance imaging of human visual cortex during face matching: a comparison with positron emission tomography. NeuroImage, 4(1):115. PMID: 9345493. http://www.sciencedirect.com/science/article/B6WNP-45MGVH01N/2/bbe55a24fee552617fe23d0e420e6753. ISSN 1053-8119.

Committeri, G., Galati, G., Paradis, A.-L., Pizzamiglio, L., Berthoz, A., and LeBihan, D. (2003). Egocentric and allocentric spatial coding in a 3D environment. NeuroImage, 19(2). http://208.164.121.55/hbm2003/. Presented at the 9th International Conference on Functional Mapping of the Human Brain, June 19-22, 2003, New York, NY. Available on CD-Rom.

Cornette, L., Dupont, P., Spileers, W., Sunaert, S., Hecke, P. V., Mortelsmans, L., and Orban, G. A. (1998). Human cerebral activity evoked by motion reversal and motion onset. Brain, 121(1):143-157. PMID: 9549495.

Creac'h, C., Henry, P., Caillé, J. M., and Allard, M. (2000). Functioal MR imaging analysis of pain-related brain activation after acute mechanical stimulation. AJNR American Journal of Neuroradiology, 21(8):1402-1406. PMID: 11003271. http://www.ajnr.org/cgi/content/full/21/8/1402. There are no Talairach coordinates.

Daselaar, S. M., Veltman, D. J., Rombouts, S. A. R. B., Raaijmakers, J. G. W., and Jonker, C. (2003). Neuroanatomical correlates of episodic encoding and retrieval in young and elderly subjects. Brain, 126(Pt 1):43-56. PMID: 12477696. ISSN 0006-8950.

Desgranges, B., Baron, J. C., and Eustache, F. (1998). The functional neuroanatomy of episodic memory: the role of the frontal lobes, the hippocampal formation, and other areas. NeuroImage, 8(2):198-213. PMID: 9740762.

Dhillon, I. and Modha, D. (2001). Concept decompositions for large sparse text data using clustering. Machine Learning, 42(1):143-175. http://www.cs.utexas.edu/users/inderjit/public_papers/concept_mlj.ps.gz.

Dobrokhotov, P., Goutte, C., Veuthey, A.-L., and Gaussier, E. (2003). A probabilistic information retrieval approach to medical annotation in SWISS-PROT. In Baud, R., Fieschi, M., Beux, P. L., and Ruch, P., editors, The New Navigators: from Professionals to Patients. Proceedings of MIE2003, volume 95 of Studies in Health Technology and Informatics, Amsterdam, 
The Netherlands. IOS Press. http://www.xrce.xerox.com/Publications/Attachments/2003008/dobrokhotov03probabilistic.pdf. ISBN 1586033476.

Donoho, D. and Stodden, V. (2004). When does non-negative matrix factorization give a correct decomposition into parts? In Thrun, S., Saul, L., and Schölkopf, B., editors, Advances in Neural Information Processing Systems 16, Cambridge, MA. MIT Press. http://books.nips.cc/papers/files/nips16/files/NIPS2003_LT10.pdf.

Duncan, J. and Owen, A. M. (2000). Common regions of the human frontal lobe recruited by diverse cognitive demands. Trends in Neurosciences, 23(10):475-483. http://www.sciencedirect.com/science/article/B6T0V-417MKDSF/1/48e8aad434785265d476e00c6d76ecbf. ISSN 0378-5912.

Düzel, E., Cabeza, R., Picton, T. W., Yonelinas, A. P., Scheich, H., Heinze, J.-J., and Tulving, E. (1999). Task-related and item-related brain process of memory retrieval. Proceedings of the National Academy of Sciences USA, 96(4):1794-1799.

Edgington, E. S. (1986). Randomization tests, volume 77 of Statistics: textbooks and monographs. Marcel Dekker, New York, second edition.

Elkashef, A. M., Doudet, D., Bryant, T., Cohen, R. M., Li, S.-H., and Wyatt, R. J. (2000). 6- ${ }^{18}$ FDOPA PET study in patients with schizophrenia. positron emission tomography. Psychiatry Research, 100(1):1-11. PMID: 11090720. ISSN 0165-1781. There are no Talairach coordinates.

Farrow, T. F., Zheng, Y., Wilkinson, I. D., Spence, S. A., Deakin, J. F., Tarrier, N., Griffiths, P. D., and Woodruff, P. W. (2001). Investigating the functional anatomy of empathy and forgiveness. NeuroReport, 12(11):2433-2438. PMID: 11496124. ISSN 0959-4965.

Fink, G. R., Markowitsch, H. J., Reinkemeier, M., Bruckbauer, T., Kessler, J., and Heiss, W. D. (1996). Cerebral representation of one's own past: neural networks involved in autobiographical memory. Journal of Neuroscience, 16(13):4275-4282. PMID: 8753888. WOBIB: 68. ISSN 0270-6474.

Fox, P. T., Huang, A., Parsons, L. M., Xiong, J.-H., Zamarippa, F., Rainey, L., and Lancaster, J. L. (2001). Location-probability profiles for the mouth region of human primary motor-sensory cortex: Model validation. NeuroImage, 13(1):196-209. PMID: 11133322. DOI: 10.1006/nimg.2000.0659. ISSN 1053-8119.

Fox, P. T. and Lancaster, J. L. (2002). Mapping context and content: the BrainMap model. Nature Reviews Neuroscience, 3(4):319-321. http://www.brainmapdbj.org/Fox01context.pdf. Describes the philosophy behind the (new) BrainMap functional brain imaging database with "BrainMap Experiment Coding Scheme" and tables of activation foci. Furthermore discusses financial problems and quality control of data.

Francis, S. T., Kelly, E. F., Bowtell, R., Dunseath, W. J., Folger, S. E., and McGlone, F. (2000). fMRI of the responses to vibratory stimulation of digit tips. NeuroImage, 11(3):188-202. PMID: 10694461. DOI: 10.1006/nimg.2000.0541. ISSN 1053-8119.

Fredrikson, M., Fischer, H., and Wik, G. (1997). Cerebral blood flow during anxiety provocation. Journal of Clinical Psychiatry, 58(16):16-21. PMID: 9430505. A review of four of their own previously published studies of snake and spider phobia and reexperience of traumatic events. There are no Talairach coordinates made available.

Fredrikson, M., Wik, G., Annas, P., Ericson, K., and Stone-Elander, S. (1995). Functional neuroanatomy of visually elicited simple phobic fear: additional data and theoretical analysis. Psychophysiology, 32(1):43-48. PMID: 7878168. A PET study showing rCBF decreases in the 
hippocampus, prefrontal, orbitofrontal, temporopolar and posterior cingulate cortex in connection with phobic fear. There are no Talairach coordinates.

Fujii, T., Okuda, J., Tsukiura, T., Ohtake, H., Miura, R., Fukatsu, R., Suzuki, K., Kawashima, R., Itoh, M., Fukuda, H., and Yamadori, A. (2002). The role of the basal forebrain in episodic memory retrieval: a positron emission tomography study. NeuroImage, 15(3):501-508. PMID: 11848693. WOBIB: 32.

Gaussier, E., Goutte, C., Popat, K., and Chen, F. (2002). A hierarchical model for clustering and categorising documents. In Crestani, F., Girolami, M., and can Rijsbergen, C. J., editors, Advances in Information Retrieval. 24th BCSIRSG European Colloquium on IR Research Glasgow, UK, March 25-27, 2002 Proceedings, volume 2291 of Lecture Notes in Computer Science, pages 229-247, Berlin, Germany. Springer. http://www.xrce.xerox.com/Publications/Attachments/2002004/gaussier02hierarchical.ps.gz. ISBN 3540433430.

Gautier, J. F., Chen, K., Uecker, A., Bandy, D., Frost, J., Salbe, A. D., Pratley, R. E., Lawson, M., Ravussin, E., Reiman, E. M., and Tataranni, P. A. (1999). Regions of the human brain affected during a liquid-meal taste perception in the fasting state: a positron emission tomography study. American Journal for Clinical Nutrition, 70(5):806-810. PMID: 10539739. ISSN 00029165 .

Gelnar, P. A., Krauss, B. R., Sheehe, P. R., Szeverenyi, N. M., and Apkarian, A. V. (1999). A comparative fMRI study of cortical representations for thermal painful, vibrotactile, and motor performance tasks. NeuroImage, 10(4):460-482. PMID: 10493903. DOI: 10.1006/nimg.1999.0482. WOBIB: 75. ISSN 1053-8119.

Ghaem, O., Mellet, E., Crivello, F., Tzourio, N., Mazoyer, B., Berthoz, A., and Denis, M. (1997). Mental navigation along memorized routes activates the hippocampus, precuneus, and insula. NeuroReport, 8(3):739-744. PMID: 9106758. ISSN 0959-4965.

Goldman, J. A., Chu, W. W., Parker, D. S., and Goldman, R. M. (1999). Term domain distribution analysis: a data mining tool for text databases. Methods of Information in Medicine, 38(2):96101. PMID: 10431513.

Goutte, C., Hansen, L. K., Liptrot, M. G., and Rostrup, E. (2001). Featurespace clustering for fMRI meta-analysis. Human Brain Mapping, 13(3):165-183. http://www3.interscience.wiley.com/cgi-bin/abstract/82002382/START.

Goutte, C., Toft, P., Rostrup, E., Nielsen, F. A., and Hansen, L. K. (1999). On clustering fMRI time series. NeuroImage, 9(3):298-310.

Grön, G., Wunderlich, A. P., Spitzer, M., Tomczak, R., and Riepe, M. W. (2000). Brain activation during human navigation: gender-different neural networks as substrate of performance. Nature Neuroscience, 3(4):404-408. PMID: 10725932. DOI: 10.1038/73980. ISSN 1097-6256.

Hansen, L. K., Sigursson, S., Kolenda, T., Nielsen, F. Å., Kjems, U., and Larsen, J. (2000). Modeling text with generalizable Gaussian mixtures. In Proceedings of ICASSP'2000. Turkey. http://isp.imm.dtu.dk/publications/1999/hansen.icassp2000.ps.gz. CiteSeer: http://citeseer.nj.nec.com/hansen99modeling.html.

Hofmann, T. (1999). Probabilistic latent semantic analysis. In Proceedings of the 15th Conference on Uncertainty in AI, pages 289-296. Morgan Kaufmann. CiteSeer: http://citeseer.nj.nec.com/hofmann99probabilistic.html. 
Hsieh, J.-C., Belfrage, M., Stone-Elander, S., Hansson, P., and Ingvar, M. (1995). Central representation of chronic ongoing neuropathic pain studied by positron emission tomography. Pain, 63(3):225-236. PMID: 8628589.

Hulshoff Pol, H. E., Schnack, H. G., Mandl, R. C., van Haren, N. E. M., Koning, H., Collins, D. L., Evans, A. C., and Kahn, R. S. (2001). Focal gray matter density changes in schizophrenia. Archives of General Psychiatry, 58(12):1118-1125. PMID: 11735840. ISSN 0003-990X.

Hunkin, N. M., Mayes, A. R., Gregory, L. J., Nicholas, A. K., Nunn, J. A., Brammer, M. J., Bullmore, E. T., and Williams, S. C. R. (2002). Novelty-related activation within the medial temporal lobes. Neuropsychologia, 40(8):1456-1464. PMID: 11931949. ISSN 0028-3932.

Ingvar, M. (1999). Pain and functional imaging. Philosophical Transactions of the Royal Society of London. Series B, Biological Sciences, 354(1387):1347-1358. PMID: 10466155.

Inoue, K., Kawashima, R., Satoh, K., Kinomura, S., Goto, R., Koyama, M., Sugiura, M., Ito, M., and Fukuda, H. (1998). PET study of pointing with visual feedback of moving hands. Journal of Neurophysiology, 79(1):117-125. PMID: 9425182. ISSN 0022-3077. A PET study with a head mounted display where the subjects reached for six light emitting diodes while either were able to see their own hand or not. Posterior cingulate activation appears when the subject is able to see their own hand.

Isbell Jr., C. L. and Viola, P. (1999). Restructuring sparse high dimensional data for effective retrieval. In Kearns, M. S., Solla, S. A., and Cohen, D., editors, Advances in Neural Information Processing Systems 11: Proceedings of the 1998 Conference, pages 480-486, Cambridge, Massachusetts. MIT Press. ftp://ftp.ai.mit.edu/pub/users/isbell/cluster.ps.gz. ISBN 0262112450.

Jernigan, T. L., Ostergaard, A. L., Law, I., Svarer, C., Gerlach, C., and Paulson, O. B. (1998). Brain activation during word identification and word recognition. NeuroImage, 8(1):93-105. PMID: 9698579. WOBIB: 35.

Kertzman, C., Schwarz, U., Zeffiro, T. A., and Hallett, M. (1997). The role of posterior parietal cortex in visually guided reaching movements in humans. Experimental Brain Research, 114(1):170-183. PMID: 9125463. ISSN 0014-4819.

Kilts, C. D., Egan, G. J., Gideon, D. A., Faber, T., and Hoffman, J. M. (1996). The functional organization of the human brain for face emotion perception: A PET neuroactivation analysis. NeuroImage, 3(5, part 2):S227.

Kleinberg, J. M. (1999). Authoritative sources in a hyperlinked environment. Journal of ACM, 46(5):604-632.

Kobayashi, Y. and Amaral, D. G. (2000). Macaque monkey retrosplenial cortex: I. threedimensional and cytoarchitectonic organization. The Journal of Comparative Neurology, 426(3):339-365. PMID: 10992242.

Kolenda, T., Hansen, L. K., and Sigursson, S. (2000). Independent components in text. In Girolami, M., editor, Advances in Independent Component Analysis, Perspectives on Neural Computing, chapter 13. Springer Verlag, Berlin, Germany. http://www.imm.dtu.dk/pubdb/views/edoc_download.php/830/zip/imm830.zip. ISBN 1852332638.

Krause, B. J., Horwitz, B., Taylor, J. G., Schmidt, D., Mottaghy, F. M., Herzog, H., Halsband, U., and Muller-Gartner, H. (1999). Network analysis in episodic encoding and retrieval of word-pair associates: a PET study. European Journal of Neuroscience, 11(9):3293-3301. PMID: 10510193. 
Lange, N., Strother, S. C., Anderson, J. R., Nielsen, F. A., Holmes, A. P., Kolenda, T., Savoy, R., and Hansen, L. K. (1999). Plurality and resemblance in fMRI data analysis. NeuroImage, 10(3):282-303. PMID: $10458943 . \quad$ DOI: 10.1006/nimg.1999.0472. http://www.sciencedirect.com/science/article/B6WNP-45FCP4813/2/bd7e7f72099b83540609e24c627a2fc4.

Lanius, R. A., Williamson, P. C., Densmore, M., Boksman, K., Gupta, M. A., Neufeld, R. W., Gati, J. S., and Menon, R. S. (2001). Neural correlates of traumatic memories in posttraumatic stress disorder: a functional MRI investigation. American Journal of Psychiatry, 158(11):1920-1922. PMID: 11691703. ISSN 0002-953X.

Lee, D. D. and Seung, H. S. (1999). Learning the parts of objects by non-negative matrix factorization. Nature, 401(6755):788-791. PMID: 10548103.

Lee, D. D. and Seung, H. S. (2001). Algorithms for non-negative matrix factorization. In Leen, T. K., Dietterich, T. G., and Tresp, V., editors, Advances in Neural Information Processing Systems 13: Proceedings of the 2000 Conference, pages 556-562. CiteSeer: http://citeseer.nj.nec.com/lee00algorithms.html.

Lekander, M., Fredrikson, M., and Wik, G. (2000). Neuroimmune relations in patients with fibromyalgia: a positron emission tomography study. Neuroscience Letters, 282(3):193-196. PMID: 10717424. ISSN 0304-3940.

Luna, B., Minshew, N. J., Garver, K. E., Lazar, N. A., Thulborn, K. R., Eddy, W. F., and Sweeney, J. A. (2002). Neocortical system abnormalities in autism: an fMRI study of spatial working memory. Neurology, 59(6):834-840. PMID: 12297562. ISSN 0028-3878. There are no Talairach coordinates.

Maddock, R. J. (1999). The retrosplenial cortex and emotion: new insights from functional neuroimaging of the human brain. Trends in Neurosciences, 22(7):310-316. DOI: 10.1016/S0166-2236(98)01374-5. http://www.sciencedirect.com/science/article/B6T0V408JD8J-B/2/6ece1d70a602b784489b3917f87d8818.

Maddock, R. J. and Buonocore, M. H. (1997). Activation of left posterior cingulate gyrus by the auditory presentation of threat-related words: an fMRI study. Psychiatry Research, 75(1):114. PMID: 9287369.

Maddock, R. J., Garrett, A. S., and Buonocore, M. H. (2001). Remembering familiar people: the posterior cingulate cortex and autobiographical memory retrieval. Neuroscience, 104(3):667676. PMID: 11440800. WOBIB: 90. ISSN 0306-4522. An fMRI study showing the strongest activation in the caudal part of the posterior cingulate cortex during cued recall of familiar people, — interpreted as autobiographical memory retrieval.

Maddock, R. J., Garrett, A. S., and Buonocore, M. H. (2003). Posterior cingulate cortex activation by emotional words: fmri evidence from a valence decision task. Human Brain Mapping, 18(1):30-41. PMID: 12454910. DOI: 10.1002/hbm.10075. WOBIB: 39. ISSN 1065-9471.

Maguire, E. A. (2001). The retrosplenial contribution to human navigation: A review of lesion and neuroimaging findings. Scandinavian Journal of Psychology, 42:225-238. PMID: 11501737. ISSN 0036-5564.

Maguire, E. A. and Mummery, C. J. (1999). Differential modulation of a common memory retrieval network revealed by positron emission tomography. Hippocampus, 9(1):54-61. PMID: 10088900. WOBIB: 78. ISSN 1050-9631. 
Maguire, E. A., Vargha-Khadem, F., and Mishkin, M. (2001). The effects of bilateral hippocampal damage on fMRI regional activations and interactions during memory retrieval. Brain, 124(6):1156-1170. PMID: 11353732.

Mardia, K. V. (1970). Measures of multivariate skewness and kurtosis with applications. Biometrika, 36:519-530.

Mardia, K. V., Kent, J. T., and Bibby, J. M. (1979). Multivariate Analysis. Probability and Mathematical Statistics. Academic Press, London. ISBN 0124712525.

Mazoyer, B., Zago, L., Mellet, E., Bricogne, S., Etard, O., Houde, O., Crivello, F., Joliot, M., Petit, L., and Tzourio-Mazoyer, N. (2001). Cortical networks for working memory and executive functions sustain the conscious resting state in man. Brain Research Bulletin, 54(3):287-298. PMID: 11287133. ISSN 0361-9230.

McDonald, C. R., Crosson, B., Valenstein, E., and Bowers, D. (2001). Verbal encoding deficits in a patient with a left retrosplenial lesion. Neurocase, 7(5):405-417. PMID: 11744782.

Mead, L. A., Mayer, A. R., Bobholz, J. A., Woodley, S. J., Cunningham, J. M., Hammeke, T. A., and Rao, S. M. (2002). Neural basis of the Stroop interference task: response competition or selective attention? Journal of the International Neuropsychological Society, 8(6):735-742. PMID: 12240737. ISSN 1355-6177.

Mesulam, M. M., Nobre, A. C., Kim, Y.-H., Parrish, T. B., and Gitelman, D. R. (2001). Heterogeneity of cingulate contributions to spatial attention. NeuroImage, 13(6):1065-1072. PMID: 11352612. WOBIB: 120. An fMRI study with visuospatial attention that is restricted to the cingulate cortex. Two interesting areas are found: One in ACC and one in PCC. The PCC activation are associated with fast response.

Minoshima, S., Foster, N. L., and Kuhl, D. E. (1994). Posterior cingulate cortex in Alzheimer's disease. The Lancet, 344:895.

Naliboff, B. D., Derbyshire, S. W., Munakata, J., Berman, S., Mandelkern, M., Chang, L., and Mayer, E. A. (2001). Cerebral activation in patients with irritable bowel syndrome and control subjects during rectosigmoid stimulation. Psychosomatic Medicine, 63(3):365-375. PMID: 11382264. ISSN 0033-3174.

Nielsen, F. Å. (2003). The Brede database: a small database for functional neuroimaging. NeuroImage, 19(2). http://208.164.121.55/hbm2003/abstract/abstract906.htm. Presented at the 9th International Conference on Functional Mapping of the Human Brain, June 19-22, 2003, New York, NY. Available on CD-Rom.

Nielsen, F. A. and Hansen, L. K. (2000). Experiences with Matlab and VRML in functional neuroimaging visualizations. In Klasky, S. and Thorpe, S., editors, VDE2000 - Visualization Development Environments, Workshop Proceedings, Princeton, New Jersey, USA, April 27-28, 2000, pages 76-81, Princeton, New Jersey. Princeton Plasma Physics Laboratory. http://www.imm.dtu.dk/pubdb/views/edoc_download.php/1231/pdf/imm1231.pdf. CiteSeer: http://citeseer.nj.nec.com/309470.html.

Nielsen, F. A. and Hansen, L. K. (2002). Automatic anatomical labeling of Talairach coordinates and generation of volumes of interest via the BrainMap database. NeuroImage, 16(2). http://www.imm.dtu.dk/ fn/ps/Nielsen2002Translating_abstract.ps.gz. Presented at the 8 th International Conference on Functional Mapping of the Human Brain, June 2-6, 2002, Sendai, Japan. Available on CD-Rom. 
Nielsen, F. A. and Hansen, L. K. (2004). Finding related functional neuroimaging volumes. Artificial Intelligence in Medicine, 30(2):141-151. PMID: 14992762. http://www.imm.dtu.dk/ fn/Nielsen2002Finding/.

Nybäck, H., Nyman, H., Blomqvist, G., Sjögren, I., and Stone-Elander, S. (1991). Brain metabolism in Alzheimer's dementia: studies of ${ }^{11} \mathrm{C}$-deoxyglucose accumulation, CSF monoamine metabolites and neuropsychologival test performance in patients and healthy subjects. Journal of Neurology, Neurosurgery \&3 Psychiatry, 54(8):673-678. PMID: 1719135.

Nyberg, L., McIntosh, A. R., Cabeza, R., Nilsson, L.-G., Houle, S., Habib, R., and Tulving, E. (1996). Network analysis of positron emission tomography regional cerebral blood flow data: ensemble inhibition during episodic memory retrieval. Journal of Neuroscience, 16(11):37533759. PMID: 8642418. ISSN 0270-6474.

Olson, C. R., Musil, S. Y., and Goldberg, M. E. (1996). Single neurons in posterior cingulate cortex of behaving macaque: eye movement signals. Journal of Neurophysiology, 76(5):3285-3300. PMID: 8930273.

Onoe, H., Komori, M., Onoe, K., Takechi, H., Tsukada, H., and Watanabe, Y. (2001). Cortical networks recruited for time perception: a monkey positron emission tomography (PET) study. NeuroImage, 13(1):37-45. PMID: 11133307. DOI: 10.1006/nimg.2000.0670. ISSN 1053-8119.

Pasca, M. and Harabagiu, S. (2001). High-performance question/answering. In Croft, W. B., Harper, D. J., Kraft, D. H., and Zobel, J., editors, SIGIR 2001: Proceedings of the 24th Annual International ACM SIGIR Conference on Research and Development in Information Retrieval, September 9-13, 2001, New Orleans, Louisiana, USA, pages 366-374, New York. ACM. http://www.cs.utexas.edu/users/sanda/papers/sigir01.ps.gz. ISBN 1581133316.

Peiffer, C., Poline, J.-B., Thivard, L., Aubier, M., and Samson, Y. (2001). Neural substrates for the perception of acutely induced dyspnea. American Journal of Respiratory and Critical Care Medicine, 163(4):951-957. PMID: 11282772. http://ajrccm.atsjournals.org/cgi/content/full/163/4/951. ISSN 1073-449X.

Perez-Iratxeta, C., Bork, P., and Andrade, M. A. (2001). XplorMed: a tool for exploring MEDLINE abstracts. Trends in Biochemical Sciences, 26(9):573-575.

Petrovic, P., Ingvar, M., Stone-Elander, S., Petersson, K. M., and Hansson, P. (1999). A PET activation study of dynamic mechanical allodynia in patients with mononeuropathy. Pain, 83(3):459-470. PMID: 10568854. ISSN 0304-3959.

Peyron, R., Laurent, B., and Garcia-Larrea, L. (2000). Functional imaging of brain responses to pain. a review and meta-analysis (2000). Neurophysiologie Clinique/Clinical Neurophysiology, 30(5):263-288. PMID: 11126640. ISSN 0987-7053.

Phillips, M. L., Bullmore, E. T., Howard, R., Woodruff, P. W., Wright, I. C., Williams, S. C., Simmons, A., Andrew, C., Brammer, M., and David, A. S. (1998). Investigation of facial recognition memory and happy and sad facial expression perception: an fMRI study. Psychiatry Research, 83(3):127-138. PMID: 9849722. ISSN 0165-1781.

Piefke, M., Weiss, P. H., Zilles, K., Markowitsch, H. J., and Fink, G. R. (2003). Differential remoteness and emotional tone modulate the neural correlates of autobiographical memory. Brain, 126(Part 3):650-668. PMID: 12566286. ISSN 0006-8950.

Pissiota, A., Frans, O., Fernandez, M., von Knorring, L., Fischer, H., and Fredrikson, M. (2002). Neurofunctional correlates of posttraumatic stress disorder: a PET symptom provocation study. European Archives of Psychiatry and Clinical Neuroscience, 252(2):68-75. PMID: 12111339. DOI: 10.1007/s004060200014. WOBIB: 66. 
Raichle, M. E., MacLeod, A. M., Snyder, A. Z., Powers, W. J., Gusnard, D. A., and Shulman, G. L. (2001). A default mode of brain function. Proceedings of the National Academy of Sciences USA, 98(2):676-682. PMID: 11209064. DOI: 10.1073/pnas.98.2.676. WOBIB: 55. ISSN 0027-8424.

Rainville, P., Hofbauer, R. K., Paus, T., Duncan, G. H., Bushnell, M. C., and Price, D. D. (1999). Cerebral mechanisms of hypnotic induction and suggestion. Journal of Cognitive Neuroscience, 11(1):110-125. PMID: 9950718. ISSN 0898-929X.

Rosen, S. D., Paulesu, E., Frith, C. D., Frackowiak, R. S. J., Davies, G. J., Jones, T., and Camici, P. G. (1994). Central nervous pathways mediating angina pectoris. Lancet, 344(8916):147-150. PMID: 7912763.

Salton, G. and Buckley, C. (1988). Term-weighting approaches in automatic text retrieval. Information Processing and Management, 24(5):513-523.

Salton, G., Wong, A., and Yang, C. S. (1975). A vector space model for automatic indexing. Communication of the ACM, 18:613-620.

Shah, N. J., Marshall, J. C., Zafiris, O., Schwab, A., Zilles, K., Markowitsch, H. J., and Fink, G. R. (2001). The neural correlates of person familiarity. a functional magnetic resonance imaging study with clinical implications. Brain, 124(4):804-815. PMID: 11287379. WOBIB: 64.

Shallice, T., Fletcher, P., Frith, C. D., Grasby, P., Frackowiak, R. S. J., and Dolan, R. J. (1994). Brain regions associated with acquisition and retrieval of verbal episodic memory. Nature, 368(6472):633-635. PMID: 8145849.

Shibata, H. and Yukie, M. (2003). Differential thalamic connections of the posteroventral and dorsal posterior cingulate gyrus in the monkey. European Journal of Neuroscience, 18(6):1516-1626. PMID: 14511340. DOI: 10.1046/j.1460-9568.2003.02868.x.

Shin, L. M., Kosslyn, S. M., McNally, R. J., Alpert, N. M., Thompson, W. L., Rauch, S. L., Macklin, M. L., and Pitman, R. K. (1997). Visual imagery and perception in posttraumatic stress disorder. Archives of General Psychiatry. PMID: 9075464.

Shin, L. M., McNally, R. J., Kosslyn, S. M., Thompson, W. L., Rauch, S. L., Alpert, N. M., Metzger, L. J., Lasko, N. B., Orr, S. P., and Pitman, R. K. (1999). Regional cerebral blood flow during script-driven imagery in childhood sexual abuse-related PTSD: A PET investigation. American Journal of Psychiatry, 156(4):575-584. PMID: 10200737. ISSN 0002-953X.

Shulman, G. L., Fiez, J. A., Corbetta, M., Buckner, R. L., Miezin, F. M., Raichle, M. E., and Petersen, S. E. (1997). Common blood flow changes across visual tasks: II. decreases in cerebral cortex. Journal of Cognitive Neuroscience, 9(5):648-656.

Small, D. M., Gitelman, D. R., Gregory, M. D., Nobre, A. C., Parrish, T. B., and Mesulam, M.-M. (2003). The posterior cingulate and medial prefrontal cortex mediate the anticipatory allocation of spatial attention. NeuroImage, 18(3):633-641. PMID: 12667840. WOBIB: 65. ISSN 1053-8119.

Sowell, E. R., Levitt, J., Thompson, P. M., Holmes, C. J., Blanton, R. E., Kornsand, D. S., Caplan, R., McCracken, J., Asarnow, R., and Toga, A. W. (2000). Brain abnormalities in early-onset schizophrenia spectrum disorder observed with statistical parametric mapping of structural magnetic resonance images. American Journal of Psychiatry, 157(9):1475-1484. PMID: 10964865. ISSN 0002-953X. There are no Talairach coordinates. 
Sprengelmeyer, R., Rausch, M., Eysel, U. T., and Przuntek, H. (1998). Neural structures associated with recognition of facial expressions of basic emotions. Proceedings of the Royal Society of London, Series B, Biological Sciences, 265(1409):1927-1931. PMID: 9821359. WOBIB: 97. ISSN 0962-8452.

Talairach, J. and Tournoux, P. (1988). Co-planar Stereotaxic Atlas of the Human Brain. Thieme Medical Publisher Inc, New York. ISBN 0865772932.

Tillfors, M., Furmark, T., Marteinsdottir, I., Fischer, H., Pissiota, A., Langstrom, B., and Fredrikson, M. (2001). Cerebral blood flow in subjects with social phobia during stressful speaking tasks: a PET study. American Journal of Psychiatry, 158(8):1220-1226. PMID: 11481154. WOBIB: 77. ISSN 0002-953X.

Tölle, T. R., Kaufmann, T., Siessmeier, T., Lautenbacher, S., Berthele, A., Munz, F., Zieglgansberger, W., Willoch, F., Schwaiger, M., Conrad, B., and Bartenstein, P. (1999). Region-specific encoding of sensory and affective components of pain in the human brain: a positron emission tomography correlation analysis. Annals of Neurology, 45(1):40-7. PMID: 9894875. WOBIB: 79. ISSN 0364-5134.

Tzourio-Mazoyer, N., Landeau, B., Papathanassiou, D., Crivello, F., Etard, O., Delcroix, N., Mazoyer, B., and Joliot, M. (2002). Automated anatomical labeling of activations in SPM using a macroscopic anatomical parcellation of the MNI MRI single-subject brain. NeuroImage, 15(1):273-289. http://www.idealibrary.com/links/doi/10.1006/nimg.2001.0978.

Van Horn, J. D., Gold, J. M., Esposito, G., Ostrem, J. L., Mattay, V., Weinberger, D. R., and Berman, K. F. (1998). Changing patterns of brain activation during maze learning. Brain Research, 793(1-2):29-38. PMID: 9630492.

Verne, G. N., Himes, N. C., Robinson, M. E., Gopinath, K. S., Briggs, R. W., Crosson, B., and Price, D. D. (2003). Central representation of visceral and cutaneous hypersensitivity in the irritable bowel syndrome. Pain, 103(1-2):99-110. PMID: 12749964. ISSN 0304-3959.

Vogt, B. A., Absher, J. R., and Bush, G. (2000). Human retrosplenial cortex: where is it and is it involved in emotion? Trends in Neurosciences, 23(5):195-197. PMID: 10782121. ISSN 01662236 .

Vogt, B. A., Derbyshire, S., and Jones, A. K. P. (1996). Pain processing in four regions of human cingulate cortex localized with co-registered PET and MR imaging. European Journal of Neuroscience, 8(7):1461-1473. PMID: 8758953. WOBIB: 100. ISSN 0953-816X.

Vogt, B. A., Finch, D. M., and Olson, C. R. (1992). Functional heterogeneity in cingulate cortex: The anterior executive and posterior evaluative regions. Cerebral Cortex, 2:435-443.

Vogt, B. A., Vogt, L. J., Perl, D. P., and Hof, P. R. (2001). Cytology of human caudomedial cingulate, retrosplenial, and caudal parahippocampal cortices. The Journal of Comparative Neurology, 438(3):353-376. http://www.mssm.edu/cnic/pdfs/RetrosplenialJCN.pdf.

Volkow, N. D., Zhu, W., Felder, C. A., Mueller, K., Welsh, T. F., Wang, G. J., and de Leon, M. J. (2002). Changes in brain functional homogeneity in subjects with Alzheimer's disease. Psychiatry Research, 114(1):39-50. WOBIB: 61.

Wiggs, C. L., Weisberg, J., and Martin, A. (1999). Neural correlates of semantic and episodic memory retrieval. Neuropsychologia, 37(1):103-118. PMID: 9920476.

Wik, G., Fredrikson, M., Ericson, K., Eriksson, L., Stone-Elander, S., and Greitz, T. (1993). A functional cerebral response to frightening visual stimulation. Psychiatry Research: Neuroimaging, 50(1):15-24. PMID: 8511220. ISSN 0165-1781. There are no Talairach coordinates. 
Willoch, F., Rosen, G., Tolle, T. R., Oye, I., Wester, H. J., Berner, N., Schwaiger, M., and Bartenstein, P. (2000). Phantom limb pain in the human brain: unraveling neural circuitries of phantom limb sensations using positron emission tomography. Annals of Neurology, 48(6):842849. PMID: 11117540. ISSN 0364-5134.

Yamasaki, H., LaBar, K. S., and McCarthy, G. (2002). Dissociable prefrontal brain systems for attention and emotion. Proceedings of the National Academy of Sciences USA, 99(17):1144711451. PMID: 12177452. DOI: 10.1073/pnas.182176499. ISSN 0027-8424. 